\title{
Numerical Simulation on Mechanical Ventilation- Two Case Studies with Different Operation Modes
}

\author{
Yiin-Kuen Fuh, Wei-Chi Huang and Jia-Cheng Ye
}

Additional information is available at the end of the chapter

http://dx.doi.org/10.5772/48450

\section{Introduction}

Effectiveness of CFD (Computational Fluid Dynamics) and the idea that the complex dynamics of fluid-related heat transfer and even fire might be studied numerically dates back to the significant improvement of the computer power. In fact, the fundamental conservation equations governing fluid dynamics, heat transfer, and combustion were initially developed in the field of applied physics over a century ago. However, practical mathematical models inherently complex in turbulence are relatively recent due to the explosive development of the Moore's law and computational speed [1].

The first case numerically studies the effect of ventilation rates and bathroom equipment locations on the odor removal efficiency in a bathroom model. One of the most frequently used domestic rooms is bathrooms; therefore, bathrooms are a high priority part of architectural design for many homeowners. The homeowners always want to solve bathroom problems that defecation and urination emit disgusting odors of all kinds, and Dols et al. [2] and Chung and Wang [3] have demonstrated that indoor air quality has a great effect on the productivity and health of human inhabitants. The reports of both of Sandberg et al. [4] and ASHRAE [5] present that indoor air pollutants are normally at higher concentrations than their outdoor counterparts, too. The general solution of bathroom design is the implementation of mechanical ventilation system.

In previous studies, Chung and Chiang [6] observed flow patterns and contaminate particle paths in lavatories by using a numerical simulation, and the diameter of the particle is less than $1 \mathrm{~mm}$. They used a floor exhaust ventilation system for analysis, and the target is to improve the air quality of the lavatories' environment. Their simulation results present only $1.2 \%$ and $1.5 \%$ of the contaminate particles remain in the men's and women's rooms, 
respectively. With proper ventilation system, the bathroom may have higher efficiency of purging odors in the bathroom.

Sandberg [7] ,Chung and Hsu [8] defined ventilation efficiency, local air quality index and investigated related impacts of different ventilation patterns arranged by two inlet and outlet diffusers at different locations. In modern society, problem of floor exhaust vent is complex, and tradition ventilation system is mounted a small exhaust fan in the ceiling. Its main function is the suction of moisture air and odors. The air sucked into an exhaust pipe is taken out of house, and then the bathroom becomes negative pressure to let fresh air from outdoors flow into the bathroom.

According to the study of different ventilation patterns, Tung et al. [9] have a novel idea that a mechanical ceiling-supply and wall-exhaust ventilation system remove unpleasant moist air and odors. Although the design is a typical ceiling-exhaust ventilation system, it has a significant difference in the removal of the moisture and odors. The experimental result has showed that doubling the flow rate of supply air from 8.5 to 17 air changes per hour $(\mathrm{ACH})$ leads to a moderate $4 \%$ increase in ORE, but a ventilation rate of $8.5 \mathrm{ACH}$ rates is suitable for view of energy-saving. Our study aims to increase ventilation efficiency by numerically investigating different ACH rates and Fire Dynamics Simulator (FDS) [10] is used to analyze the effect of exhaust area. Deployment of local air quality (QI) and odor removal efficiency (ORE) metrics shows great potential to quantitatively evaluate the effectiveness of odor removal in the bathroom [11]. Contaminant source non-uniformity was found to have a great influence on the QI and ORE non-uniformity, with the two tested air distribution methods.

The second case study aims to numerically investigate the operation modes of mechanical ventilation in underground tunnels and compare the effectiveness of CFD with full-scale experiments and existing fire codes in Taiwan. In underground railroad tunnels and subway stations, direct exposure to fire is typically not the most immediate threat to passengers' lives. Instead, smoke inhalation due extreme heat and toxic gases is the main cause of fatality. For fire safety and hazard mitigation reasons, it is of great importance to investigate the mechanisms thermal-induced smoke motion. On the other hand, the current performance-based fire codes in Taiwan for special structures require full-scale tests [12] to experimentally investigate the effectiveness of the smoke control systems in subway stations before opening for public service. One key feature of fire-induced phenomena is called chimney or stack effect [13], which plays a significant role in the smoke control of subway stations due to various structures of vertical spaces exist such that the buoyancy force of hot smoke will be greatly enhanced.

Due to land scarcity in greater Taipei area, continuously conversion from existing railroad to underground are performed to increase the land utility at different phases and span many years. In addition, integration issues between several transportation systems such as mass transit and high speed rail are also of great concerns. Fourth phase of Nangkang North Tunnel was completed and in full operation in September, 2009. During the construction period, fire codes in Taiwan for special constructions (e.g. underground stations) are also going through various revisions while internationally, new regulations such as AS 4391 in 
Australia [14] and NFPA130 in USA [15] have been validated and updated. In order to verify the compliance of fire codes nationally and internationally, full scale experiments have been performed before actual operation with emphasis on various operation modes of mechanical ventilation. This paper aims to numerically investigate and compare the effectiveness of CFD with experimental results. Typical road tunnel fire with different causes and kinds of fire were numerically analyzed before and the temperature and visibility of tunnel zone were calculated [16]. The simulation results show that the highest central axis section reaches to $1000^{\circ} \mathrm{C}$, and the highest temperature of side wall reaches to $989^{\circ} \mathrm{C}$ under large fire scales. [17] Furthermore, other tunnel fires are also of great concern due to catastrophic fatality and numerically simulated such as Howard Street Tunnel Fire [17], tunnel fire and tunnel lining failure [18], road tunnels and ventilation effects [19]. On the other hand, smoke control of fires in subway stations and stack effects on smoke propagation are simulated and compared with experiments with great accuracy [20,21]. Ventilation strategies and application to fire in a long tunnel has been considered [22] and ordinary and emergency ventilations are operated by using dedicated supply and extraction ducts. Another key parameter for tunnel fires is the critical speed and simulation results show a good correlation with real fires [23].

According to current fire codes in Taiwan, a recent version which includes performancebased tests is stipulated in 2008 [12] for the purpose of aiding a complete implementation of fire equipments in underground tunnels and subway stations. In chapter 3 of the fire code, one exception is that simulation study is allowed for the difficult-to-test circumstances, but need to be examined by a special committee on a case-by-case basis. In particular, ventilation is a crucial element while managing fire events in tunnels and control strategy for fire-induced smoke is of great concern. Adoption of numerical simulation a validation tool is probably pioneered in NFPA130 2003, version [15] emergency smoke management session of 7.1.2.4. The first full-scale experiment in Taiwan is the Banciao station in 1999 and the actual tests also laid a foundation of performance-based fire codes for future implementation [24]. In what follows various subway stations [25-27] necessitate the full-scale tests and several reports have been reviewed and published before opening to the public service.

\section{Theoretical background}

In this section, we briefly present the governing equations of FDS and an outline of the general solution procedure which we used for all the simulations. Details of the individual equations are described in original technical guide [1]. The governing equations are essentially a complete set of partial differential equations with appropriate simplifications and approximations noted. The numerical method consists of a finite difference approximation of the governing equations and a procedure for updating these equations in time [1].

\subsection{Secondary heading, left justified}

The basic conservation equations for mass, momentum and energy for a Newtonian fluid can be found in almost any textbook on fluid dynamics or CFD. FDS adopts a description of the equations, the notation used, and the various approximations employed in Anderson et al. [28]. Note that this is a set of partial differential equations consisting of six equations for 
six unknowns, all functions of three spatial dimensions and time: the density $\mathrm{r}$, the three components of velocity $\mathrm{u}=[\mathrm{u} ; \mathrm{v} ; \mathrm{w}]^{\mathrm{T}}$, the temperature $\mathrm{T}$, and the pressure $\mathrm{p}$.

\subsubsection{Mass and species transport}

Mass conservation can be expressed either in terms of the density, @,

$$
\frac{\partial \rho}{\partial t}+\nabla \cdot \rho \mathrm{u}=\dot{m}_{b}^{\prime \prime}
$$

Here $\dot{m}_{b}^{\prime \prime \prime}$ is the mass production rate by evaporating droplets/particles.

\subsubsection{Momentum transport}

The momentum equation in conservative form is written:

$$
\frac{\partial}{\partial \mathrm{t}}(\rho \mathrm{u})+\nabla \cdot \rho \mathrm{uu}+\nabla \mathrm{p}=\rho \mathrm{g}+\mathrm{f}_{b}+\nabla \cdot \tau_{i j}
$$

The term $u$ is a diadic tensor. In matrix notation, with $u=[u ; v ; w]^{T}$, the diadic is given by the tensor product of the vectors $u$ and $u^{\wedge} \mathrm{T}$. The term $\nabla$. $\rho \mathrm{uu}$ is thus a vector formed by applying the vector operator $\nabla=\left(\frac{\partial}{\partial x}, \frac{\partial}{\partial y}, \frac{\partial}{\partial z}\right)$ to the tensor. The force term $f_{b}$ in the momentum equation represents external forces such as the drag exerted by liquid droplets. The stress tensor $\tau_{i j}$ is defined:

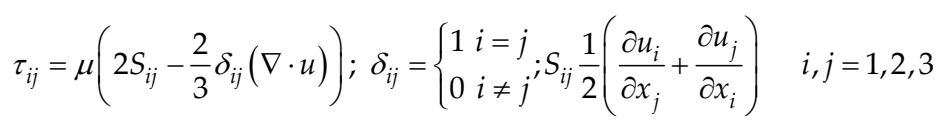

The term $S_{i j}$ is the symmetric rate-of-strain tensor, written using conventional tensor notation. The symbol $\mu$ is the dynamic viscosity of the fluid.

\subsubsection{Energy transport}

The energy conservation equation is written in terms of the sensible enthalpy, $h_{s}$ :

$$
\frac{\partial}{\partial t}\left(\rho h_{s}\right)+\nabla \cdot \rho h_{s} u=\frac{D p}{D t}+\dot{q}^{\prime \prime \prime}-\dot{q}_{b}^{\prime \prime \prime}-\nabla \cdot \dot{q}+\varepsilon
$$

The sensible enthalpy is a function of the temperature:

$$
h_{s}=\sum_{\alpha} Y_{\alpha} h_{s, \alpha} ; h_{s, \alpha}(T)=\int_{T_{0}}^{T} c_{p, \alpha}\left(T^{\prime}\right) d T^{\prime}
$$


Note the use of the material derivative, $D() / D t=\partial() / \partial t+u \cdot \nabla()$. The term $\dot{q}^{\prime \prime \prime}$ is the heat release rate per unit volume from a chemical reaction. The term $\dot{q}_{b}^{\prime \prime}$ is the energy transferred to the evaporating droplets.

The term $\dot{q} \quad$ represents the conductive and radiative heat fluxes:II

$$
\dot{q}^{\prime \prime}=-k \nabla T-\sum_{\alpha} h_{s, \alpha} \rho D_{\alpha} \nabla Y_{\alpha}+\dot{q}_{r}^{\prime \prime}
$$

where $\mathrm{k}$ is the thermal conductivity.

\subsubsection{Equation of state}

An approximate form of the Navier-Stokes equations appropriate for low Mach number applications is used in the model.

$$
\mathrm{p}=\frac{\rho R T}{\bar{W}}
$$

Here $\bar{W}$ is the molecular weight of the gas mixture.

\subsection{Solution procedure}

FDS uses a second-order accurate finite-difference approximation to the governing equations on a series of connected recti-linear meshes. The flow variables are updated in time using an explicit second-order Runge-Kutta scheme. The typical solution algorithm is used as the following to advance in time the density, species mass fractions, velocity components, and background and perturbation pressure. Let $\rho^{n}, Y_{\alpha}^{n}, u^{n}, \bar{p}_{m}^{n}$ and $H^{n}$ denote these variables at the nth time step. [1]

1. Compute the "average" velocity field $\bar{u}^{n}$.

2. Estimate $\rho, Y_{\alpha}$ and $\bar{p}_{m}$ at the next time step with an explicit Euler step. For example, the density is estimated by

$$
\frac{\rho^{*}-\rho^{n}}{\delta t}+\nabla \cdot \rho^{n} \bar{u}^{n}=0
$$

3. Exchange values of $\rho^{*}$ and $Y_{\alpha}^{*}$ at mesh boundaries.

4. Apply boundary conditions for $\rho^{*}$ and $Y_{\alpha}^{*}$

5. Compute the divergence, $\nabla \cdot \bar{u}^{*}$, using the estimated thermodynamic quantities.

6. Solve the Poisson equation for the pressure fluctuation with a direct solver on each individual mesh:

$$
\nabla^{2} H^{n}=-\left[\frac{\nabla \cdot u^{*}-\nabla \cdot \bar{u}^{n}}{\delta t}\right]-\nabla \cdot \bar{F}^{n}
$$


7. Estimate the velocity at the next time step

$$
\frac{u^{*}-\bar{u}^{n}}{\delta t}+\bar{F}^{n}+\nabla H^{n}=0
$$

8. Check the time step at this point to ensure that the stability criteria are satisfied

$$
\delta \mathrm{t} \max \left(\frac{|u|}{\delta x}, \frac{|v|}{\delta y}, \frac{|w|}{\delta z}\right)<1 ; 2 \delta t v\left(\frac{1}{\delta x^{2}}+\frac{1}{\delta y^{2}}+\frac{1}{\delta z^{2}}\right)<1
$$

This concludes the "Predictor" stage of the time step. Next the "corrector" stage follows:

1. Compute the "average" velocity field $\bar{u}^{*}$.

2. Apply the second part of the Runge-Kutta update to the mass variables. For example, the density is corrected

$$
\frac{u^{*}-\bar{u}^{n}}{\delta t}+\bar{F}^{n}+\nabla H^{n}=0
$$

3. Exchange values of $\rho^{n}$ and $Y_{\alpha}^{n}$ at mesh boundaries.

4. Apply boundary conditions for $\rho^{n}$ and $Y_{\alpha}^{n}$.

5. Compute the divergence $\nabla \cdot u^{n+1}$ from the corrected thermodynamic quantities.

6. Compute the pressure fluctuation using estimated quantities

$$
\nabla^{2} H^{*}=-\left[\frac{\nabla \cdot u^{n+1}-\frac{1}{2}\left(\nabla \cdot \bar{u}^{*}+\nabla \cdot \bar{u}^{n}\right)}{\delta t / 2}\right]-\nabla \cdot \bar{F}^{*} .
$$

7. Update the velocity via the second part of the Runge-Kutta scheme

$$
\frac{u^{n+1}-\frac{1}{2}\left(\bar{u}^{*}+\bar{u}^{n}\right)}{\delta t / 2}+\bar{F}^{*}+\nabla H^{*}=0
$$

8. At the conclusion of the time step, values of $H^{*}$ and the components of $u^{n+1}$ are exchanged at mesh boundaries via MPI calls.

The details of the predictor-corrector scheme can be found in [1].

\section{Mechanical ventilation simulation - Case1}

We use FDS to build a virtual-model bathroom dimension which is $2.36 \mathrm{~m}$ (length), $2.22 \mathrm{~m}$ (width), and $2.36 \mathrm{~m}$ (height), shown in Fig. 1(a). Bathroom facilities included a bathtub, a sink, and a toilet in the bathroom model. The red, blue, and purple model represents a bathtub, a sink, and a toilet, respectively. In the ceiling, the red square replaces the supply air 
vent (a mechanical fan), and dimensions are $0.2 \mathrm{~m}$ (length) and $0.4 \mathrm{~m}$ (width). On the wall, the red square replaces the exhaust air vent (a free opening), and dimensions are $0.2 \mathrm{~m}$ and 0.4 (length \& height), respectively. The exhaust airflow rate was 1.15 times the supply airflow rate.

\subsection{Toilet position, $\mathrm{ACH}$ rate, and exhaust vent area}

Malodorous volatile is frequently manufactured from human feces and urine in bathrooms. The odor source is created on the virtual toilet of bathroom model. This paper follows previous study [9] that assume different distances, which is the distance between the odor source and the wall-exhaust vent. As shown in Fig. 1(b), there are cases of three different distances contained $0.8 \mathrm{~m}$ (Case 1), $1.1 \mathrm{~m}$ (Case 2), and $2.05 \mathrm{~m}$ (Case 3) in this study with ventilation condition of 8.5 Air Change per Hour $(\mathrm{ACH})$.

a

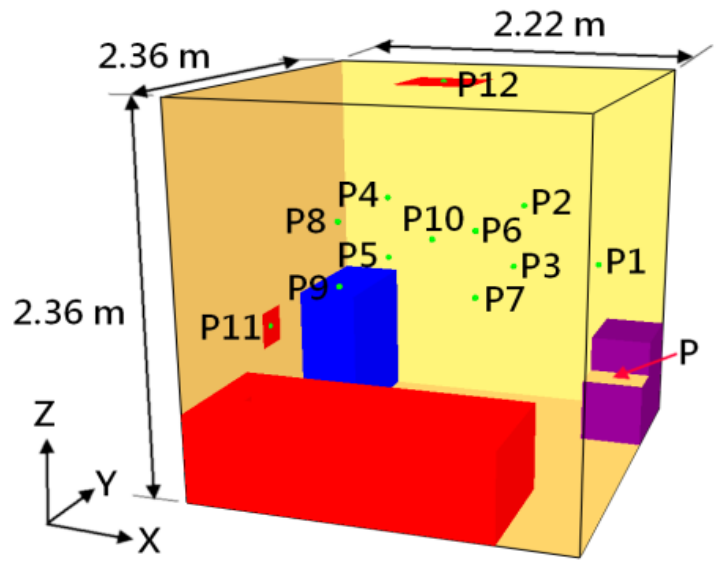

b

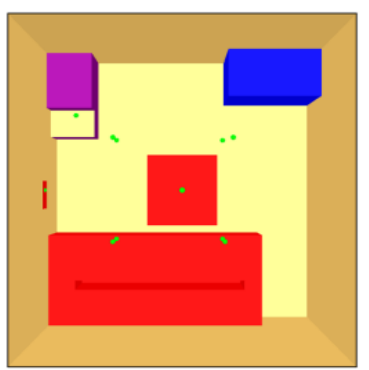

Case 1

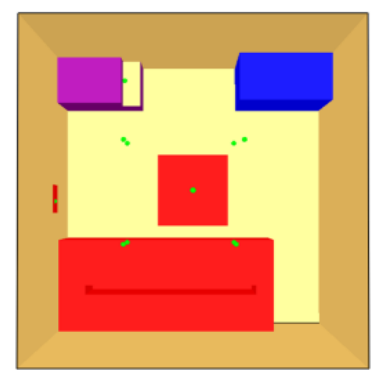

Case 2

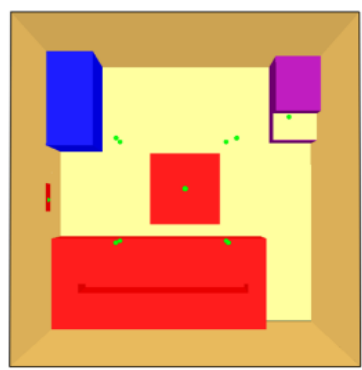

Case 3

Figure 1. (a) A mock-up bathroom used to analyze the influence of ventilation rates $6.5,8.5,17$, and 24 $\mathrm{ACH}$ on the odor removal and shows numerically measured locations of sampling points [9]. (b) In three cases, it reveals related position of bathroom facilities.

According to experiment of the previous study, our study set some issues of four different $\mathrm{ACH}$ rates in case 3, and they divide 6.5, 8.5, 17, and $24 \mathrm{ACH}$ rates. Besides, we also change 
area of wall-exhaust vents contained two cases. One case is $0.24 \mathrm{~m}$ (length) and $0.24 \mathrm{~m}$ (height), the other is $0.24 \mathrm{~m}$ (length) and $0.48 \mathrm{~m}$ (height).

\subsection{Set concentration sensor position and produce odor source position}

By setting a total of 12 concentration sensors, we can gain odor distribution data at specific positions. Odor flow pattern can be obtained and Table 1 shows positions of collected data from P1 to P12. Marked as P and P1-P12 in Fig. 3, ten measuring points (P1-P10) within the bathroom were selected to monitor the concentration levels of odors at these locations, and two extra measuring points were setup outside the room, one (P11) behind the exhaust air vent and another (P12) in front of the supply air vent; moreover, $\mathrm{P}$ was the location of a source of odors generated by a person sitting on the toilet in the bathroom.

\begin{tabular}{|c|c|c|c|}
\hline Sampling location & X-direction (m) & Y-direction (m) & Z-direction (m) \\
\hline \multicolumn{4}{|l|}{ P1 } \\
\hline Case 1 & 0.30 & 1.78 & 1.16 \\
\hline Case 2 & 0.59 & 2.08 & 1.16 \\
\hline Case 3 & 1.90 & 1.78 & 1.16 \\
\hline P2 & 1.42 & 1.58 & 1.56 \\
\hline P3 & 1.42 & 1.58 & 1.16 \\
\hline P4 & 0.61 & 1.58 & 1.56 \\
\hline P5 & 0.61 & 1.58 & 1.16 \\
\hline P6 & 1.42 & 0.79 & 1.56 \\
\hline P7 & 1.42 & 0.79 & 1.16 \\
\hline P8 & 0.61 & 0.79 & 1.56 \\
\hline P9 & 0.61 & 0.79 & 1.16 \\
\hline P10 & 1.04 & 1.17 & 1.40 \\
\hline P11 & 0.00 & 1.12 & 0.76 \\
\hline P12 & 1.11 & 1.18 & 2.36 \\
\hline \multicolumn{4}{|l|}{ Oder emission } \\
\hline \multicolumn{4}{|l|}{$\mathrm{P}$} \\
\hline Case 1 & 0.50 & 2.07 & 0.40 \\
\hline Case 2 & 0.50 & 2.07 & 0.40 \\
\hline Case 3 & 1.90 & 1.86 & 0.40 \\
\hline
\end{tabular}

Table 1. Locations of sampling points and odor emission from experimental data [9]. 


\subsection{Local air quality index}

This study followed the same definition and employed a local air quality index to describe the ventilation system's efficiency in removing odors $[9,29,30]$. A higher score on the local air quality index indicates a better ventilation efficiency due to a lower concentration level. The local air quality index, QI, is defined as follows:

$$
\mathrm{QI}=\frac{C_{e}-C_{s}}{C_{p}-C_{s}}
$$

where $C_{e}$ and $C_{s}$ are, respectively, concentrations of odors at exhaust and supply air vents. $C_{p}$ is the concentration of odors at any place $\mathrm{P}$ in the bathroom.

\subsection{Odor removal efficiency}

Again the same terminology of odor removal efficiency was used to express the ventilation efficiency of the whole bathroom [9, 30,31]. A lower index indicated a greater difficulty in the removal of odors. The odor removal efficiency, ORE, is defined as follows:

$$
\text { ORE }=\frac{C_{e}-C_{s}}{C_{b}-C_{s}}
$$

where $C_{e}$ and $C_{s}$ are concentrations of odors at exhaust and supply air vents, respectively, and $C_{b}$ is the average concentration of odors in the bathroom.

\subsection{Effects of ventilation rates}

As illustrated in Fig. 2(a), the concentration of odors at the 12 observing points (P1-P12) was examined. In these four cases, P1 revealed that odor concentration higher than odor concentration of other pieces points in $6.5 \mathrm{ACH}$ rates, since it's the shortest distance from toilet. We have found the effect of high temperature led to thermally induced buoyancy such that particle concentration of the higher levels observing points are smaller than the lower level counterparts. Points P2, P4, P6, and P8 were positioned under the ceiling-supply vent and at a relative height of 0.66 of the room height [9]; hence, their concentrations were more than the concentration of points P3, P5, P7, and P9. Numerically, the concentration profile of odors in the cases of $8.5,17$ and $24 \mathrm{ACH}$ was similar to the one in the case of 6.5 $\mathrm{ACH}$ and this result is in agreement to experiments [9]. Similar agreement between simulation and experiment is found that higher room ventilation rates resulted in lower absolute concentration levels of odors.

As shown in Fig. 2(b), it was numerically observed that changes in the room ventilation rate affected QI in a significant way at 10 points in the bathroom. All numerically monitored points in the case of $6.5 \mathrm{ACH}$ had a smaller QI than those same points in the cases of 8.5, 17, 
and $24 \mathrm{ACH}$. It was noted that the experimentally observed QI values were less than 1.0 at many points with low ventilation rate as compared to numerical values of 1.2. Small discrepancy exist while the same conclusion can be drawn that the ventilation rate of 6.5 $\mathrm{ACH}$ is not suitable the bathroom ventilation system. Both numerical and experimental results suggest the cases of $8.5,17$, and $24 \mathrm{ACH}$ had better ventilation efficiency due to QI levels were more than 1.2. Furthermore, a higher ventilation rate resulted in less spreading of odors and improved the local air quality in the bathroom.

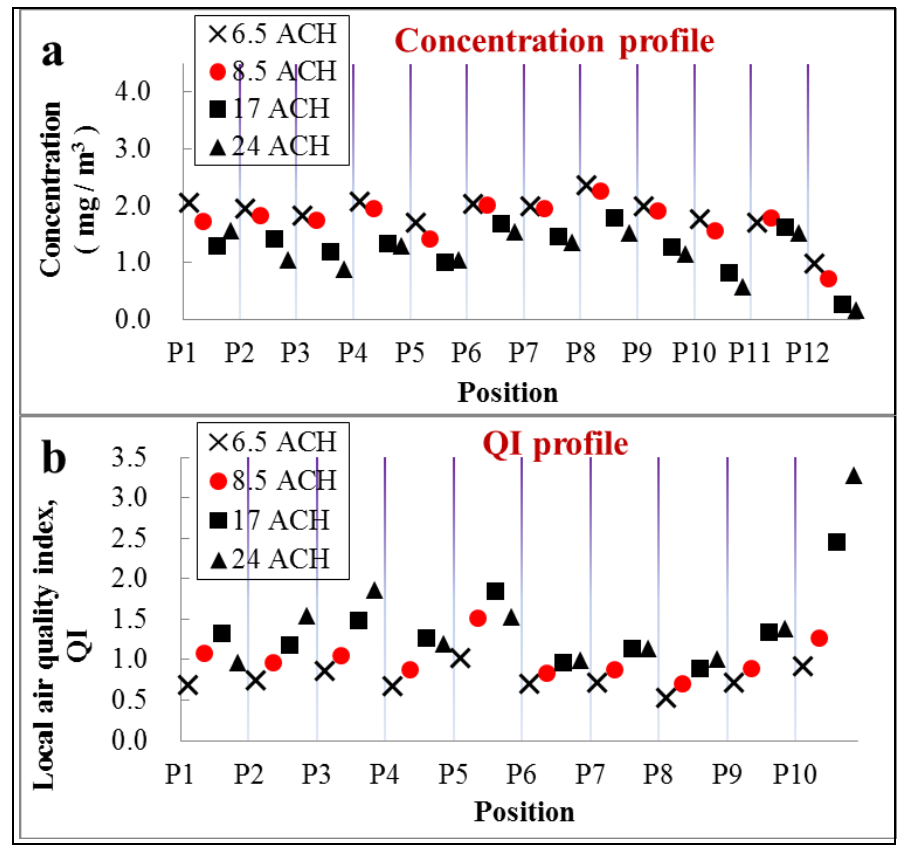

Figure 2. Effect of ventilation rates on (a) Concentration profile and (b) QI profile

\subsection{Effects of doubling exhaust-vent area}

As illustrated in Fig. 3(a), the concentration of odors at the 12 observing points (P1-P12) was examined. In these four cases of doubling exhaust-vent area, P1 revealed that odor concentration higher than odor concentration of other pieces points in $6.5 \mathrm{ACH}$ rates, since it's the shortest distance from toilet to there. We have found the effect of high temperature led to thermally induced buoyancy such that particle concentration of the higher levels observing points is smaller than the lower level counterparts. Points P2, P4, P6, and P8 were positioned under the ceiling-supply vent and at a relative height of 0.66 of the room height [9] ; hence, their concentration was more than the concentration of points P3, P5, P7, and P9, which were positioned at a relative height of 0.49. As shown in Fig. 3(b), it was numerically observed that the QI values were less than 1.3 at many points with this low ventilation rate, further improvement from 1.2 when doubling the exhaust-vent area. 


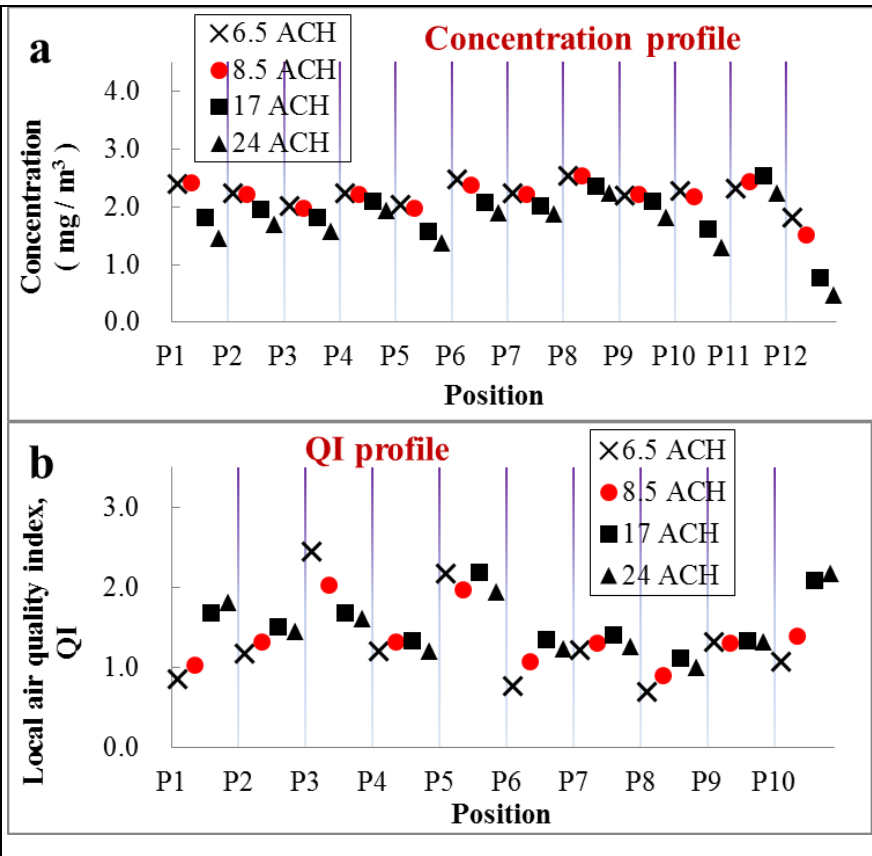

Figure 3. Effect of doubling exhaust-vent area on (a) Concentration profile and (b) QI profile.

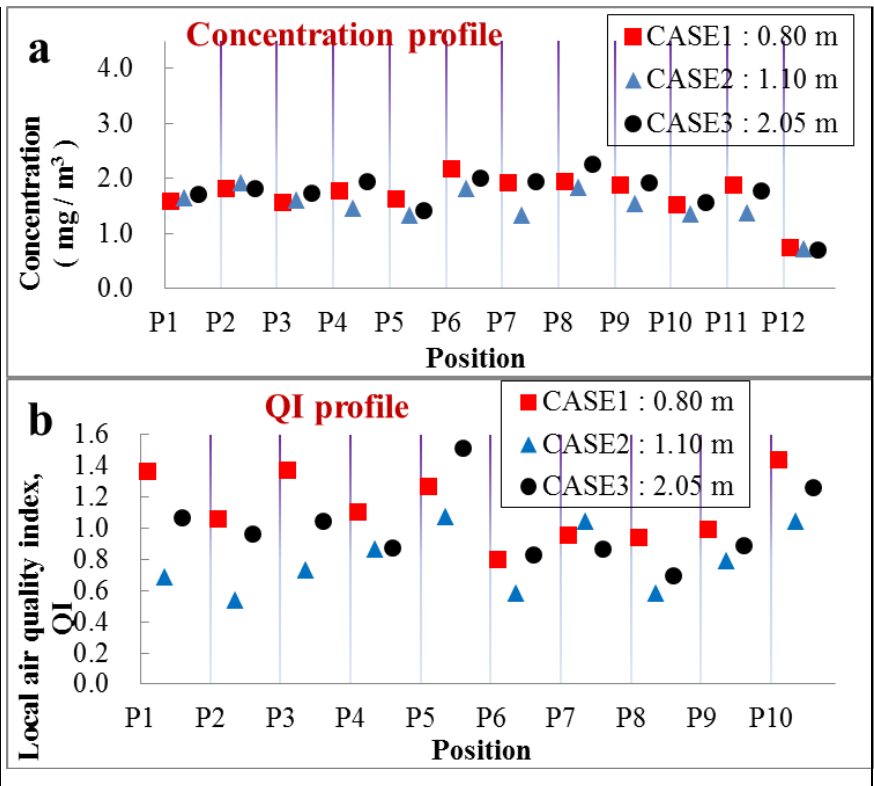

Figure 4. Effect of locations of a toilet on (a) Concentration profile and (b) QI profile. 


\subsection{Effects of location of the toilet}

The present study numerically investigated three different locations of the toilet in the bathroom and compared with experiments [9]. The distance from the exhaust air vent to the toilet (L) was $0.8,1.1$, and $2.05 \mathrm{~m}$ for Cases 1, 2, and 3, respectively. In all three cases, as seen in Fig. 4(a), point P1 reported the highest concentration of odors because this was the nearest location to the source of odors, which is in good agreement with reported data [9]. Similarly, the odor concentration at P1 in Cases 1 and 2 was lower than the concentration in Case 3 due to the fact that toilet in Cases 1 and 2 was in close proximity to the exhaust air vent than in Case 3 and thus had lower odor concentration than Case 3.

Fig. 4(b) shows calculation results that changes in L affected QI at 10 points in the bathroom. It was observed numerically that most observed points in Case 1 had the highest QI, and that their QI levels were more than 0.6 [9]. In summary, Case 1 had the best ventilation efficiency among the three cases, which is in consistent with measured data.

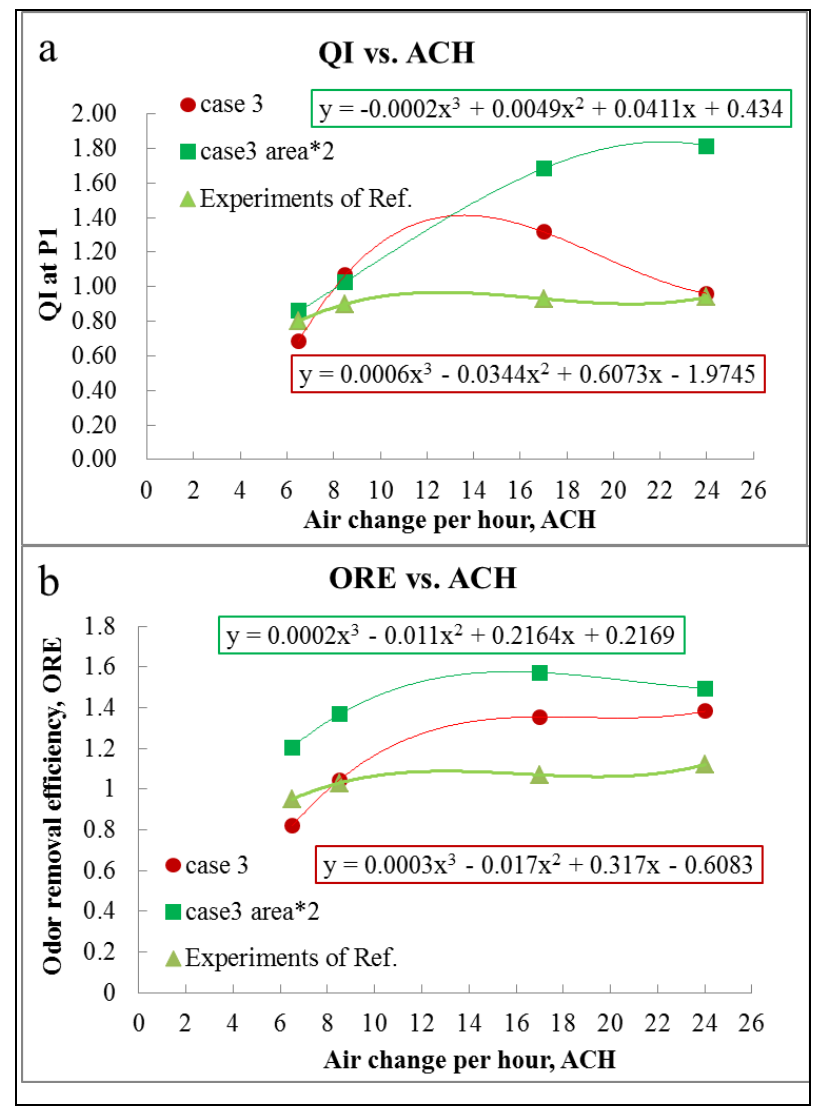

Figure 5. (a) Effectiveness analysis of QI at various ACH and comparison with experiments [9]. (b) Effectiveness analysis of ORE at various $\mathrm{ACH}$ and comparison with experiments [9]. 


\subsection{Air change rate and odor removal analysis}

A curve fitting performed using 3 order polynomial with numerically simulation's data. Fig. 5(a) show QI values of $\mathrm{P} 1$ in the different $\mathrm{ACH}$ rates and the curve fitting these QI values. The curve and point plotted in figure present relation between the different $\mathrm{ACH}$ rates and $\mathrm{QI}$, and they illustrate trend that what $\mathrm{ACH}$ rates have the best QI value. The light green curve, red curve, and green curve are the experimental data from previous study [9], data in case 3, and data with doubling exhaust-vent area in case 3. The red curve is similar to the light green one, and the trends of both are very near. The Green curve has the translation because the mesh of numerical simulations is not fine enough and turbulent flow partly results in this impact.

Fig. 5(b) shows ORE values in the different ACH rates and the curve fitting ORE values. The curve and point plotted in figure present relation between the different $\mathrm{ACH}$ rates and ORE, and they illustrate trend that what $\mathrm{ACH}$ rates have the best ORE value. The curve and point plotted in figure present relation between the different $\mathrm{ACH}$ rates and QI, and they illustrate trend that what $\mathrm{ACH}$ rates have the best QI value. The light green curve, red curve, and green curve are the experimental data from previous study [9], data in case 3, and data with doubling exhaust-vent area in case 3. The red curve and green are similar to the light green one, and the trends are very similar. The ORE value with doubling area of exhaust vent is higher other ORE value in any ACH rates. Doubling area of exhaust vents from $0.0576 \mathrm{~m} 2$ to $0.1152 \mathrm{~m} 2$ leads to a moderate $30 \%$ increase in ORE in $8.5 \mathrm{ACH}$ rates. At the same condition, it leads to a moderate $16 \%$ increase in ORE in $17 \mathrm{ACH}$ rates.

\section{Mechanical ventilation simulation- Case2}

Smoke accumulation and migration are two main fire hazards in tunnel fires. The worst case scenario happens when the mechanical ventilation fails. Therefore, how to design a fail-safe system in underground station is of great importance. Typically, effective egress time is calculated as the smoke layer descends till 1.8 meter above the ground. In this study, we simultaneously compare the experiments and CFD simulations regarding two different fire loads of 1 and 5MW for 6 minutes and 20 minutes, respectively.

Fire dynamics simulator, FDS 6.0 [10] is a computational fluid dynamics model of firedriven fluid flow. The software solves numerically a tform of the Navier-Stokes equations appropriate for low-speed, thermally-driven flow, with an emphasis on smoke and heat transport from fires. Figure 6 shows the schematics of underground railroad station constructed using FDS software. It is noted that two underground levels, B1 and B2, are simulated based on actual dimensions. Moreover, two rectangular openings in $4 m^{*} 5 m^{*} 0.3 m$ shown in Fig. 1 are used to represent the escalator positions between two underground levels. Total dimensions of $16 \mathrm{~m}^{*} 130 \mathrm{~m} * 10 \mathrm{~m}$ space are simulated with a total of more than 3 million computational grids in FDS model. Underground station is shown in blue colour with dimension of $8 \mathrm{~m}^{*} 130 \mathrm{~m}^{*} 1 \mathrm{~m}$ while the wall thickness between B1 and $\mathrm{B} 2$ is $30 \mathrm{~cm}$ (as shown in red). Experimentally, two different fire loads of 1 and $5 \mathrm{MW}$ are 
ignited at the centre of underground station using the standard methods $[14,15]$ and the smoke descending positions are measured across the station area at 6 and 20 minutes, respectively.

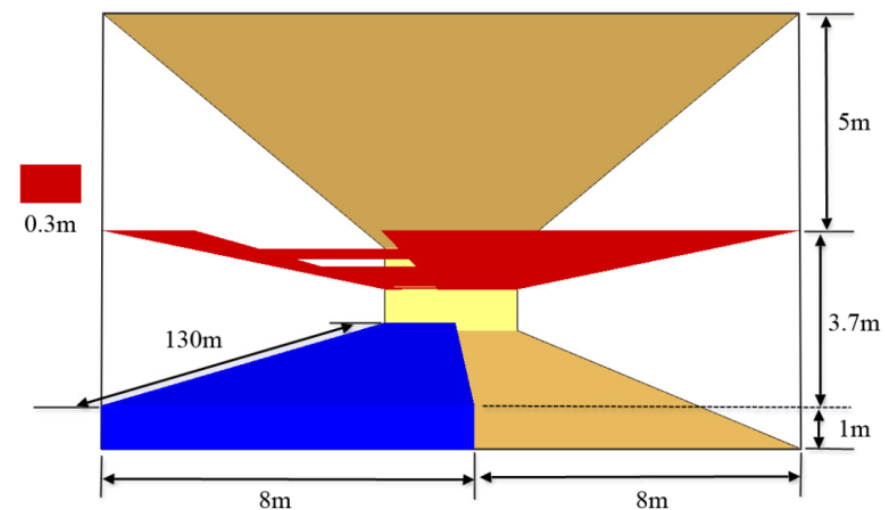

Platform area

Floor between B1 and B2. Two openings are for escalators.

Figure 6. Schematics of underground railroad station constructed using FDS software. Two underground levels, B1 and B2, are simulated and two rectangular openings are used to represent the escalator positions between two underground levels.

\subsection{Operation mode 1 , all mechanical ventilations are fail or idle}

Numerically, smoke patterns under fire load of 1 and 5 MW at time span of 360 and 1200 seconds are shown in Fig 7-8, respectively. It is noted that all mechanical ventilations are set to be in-operation to simulate the worst case scenario of mechanical failures. The particle function in FDS is used as a representation of smoke patterns. According to the fire code of NFPA130, 4 minutes of egression time is required and the key is to avoid smoke descending below $1.8 \mathrm{~m}$. For both fire loads at 1 and $5 \mathrm{MW}$, we can observe that smoke particles occupy less than $5 \%$ in area in terms of $1.8 \mathrm{~m}$ height, especially in the escalator positions. It is considered that the simulation results in compliance with NFPA130 and agrees well with full scale experiments. Accordingly, 20 minutes of smoke accumulation and migration due to forced convection for both 1 and 5 MW fires will result in 50\% and 99\% smoke layers below $1.8 \mathrm{~m}$ in escalator areas, which are considered hazardous for egression and unable to escape.

We can summarize the simulation results and compare with previous experiments for 1MW fire load after 6 minutes in table 2. Generally speaking, simulations results are in a good agreement with experimental observations. For the experiment, only visual observations by the inspectors may not be able to detect accumulation of smoke layer, especially when the smoke in little in volume and transparency optically. However, computer simulations enable us to numerically visualize the smoke at any location and scientifically calculate any 
vital information required. In this case, smoke layer height is of great importance due to egress needs, we can calculate tiny smoke accumulation in the areas located at as front and back station. Numerically, we can find less than $5 \%$ in area for smoke height $<1.8 \mathrm{~m}$ at both front and back station and the reason is because the escalator/stair induced chimney effect. Overall, both simulation and experiment are in good agreement and according to the fire code of NFPA130, 4 minutes of egression time is satisfied with $50 \%$ allowance time before smoke descending below $1.8 \mathrm{~m}$.

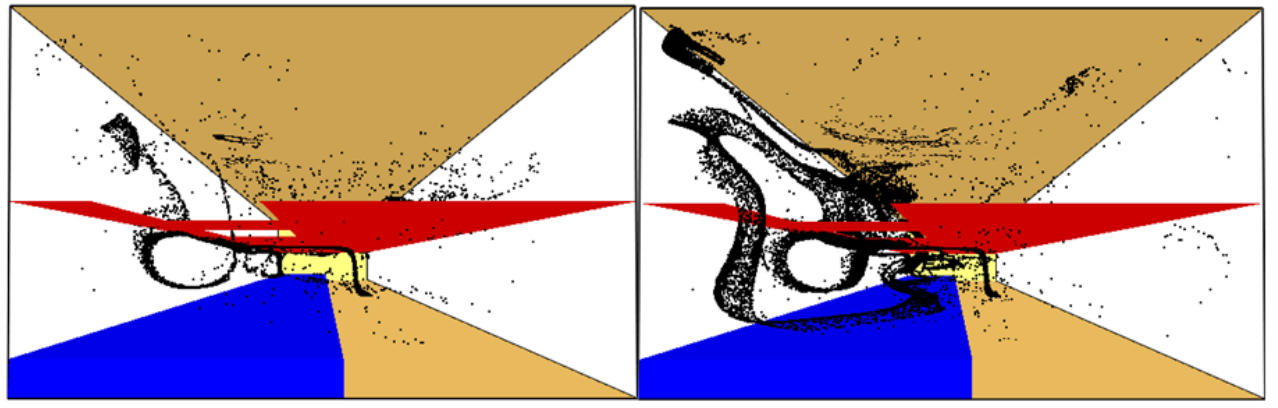

Figure 7. Smoke patterns under fire of $1 \mathrm{MW}$ at (a) 360 s and (b) 1200 s, respectively

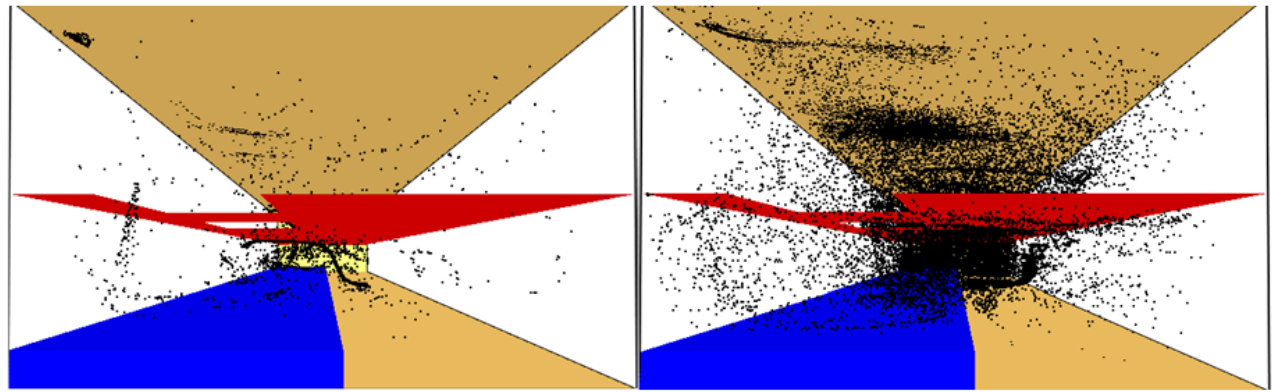

Figure 8. Smoke patterns under fire of 5MW at (a) 360s and (b) 1200s, respectively

\begin{tabular}{|c|c|c|c|c|}
\hline Area & Location & $\begin{array}{c}\text { Front } \\
\text { (5m from walls })\end{array}$ & Center & $\begin{array}{c}\text { Back } \\
(5 \mathrm{~m} \text { from walls })\end{array}$ \\
\hline Simulation & Station & $\begin{array}{c}\text { smoke height }<1.8 \mathrm{~m} \\
<5 \% \text { in area for } \\
\text { smoke height }<1.8 \mathrm{~m}\end{array}$ & Higher than $1.8 \mathrm{~m}$ & $\begin{array}{c}<\% \text { in area for smoke } \\
\text { height }<1.8 \mathrm{~m}\end{array}$ \\
\hline $\begin{array}{c}\text { Experiment } \\
{[27]}\end{array}$ & $\begin{array}{c}\text { Tunnel } \\
\text { Station }\end{array}$ & $\begin{array}{c}\text { Higher than } 1.8 \mathrm{~m} \\
\text { Higher than } 1.8 \mathrm{~m}\end{array}$ & $\begin{array}{l}\text { Higher than } 1.8 \mathrm{~m} \\
\text { Higher than } 1.8 \mathrm{~m}\end{array}$ & $\begin{array}{c}\text { Higher than } 1.8 \mathrm{~m} \\
\text { Higher than } 1.8 \mathrm{~m}\end{array}$ \\
\hline
\end{tabular}

Table 2. Comparison of simulation results and experimental observations. 


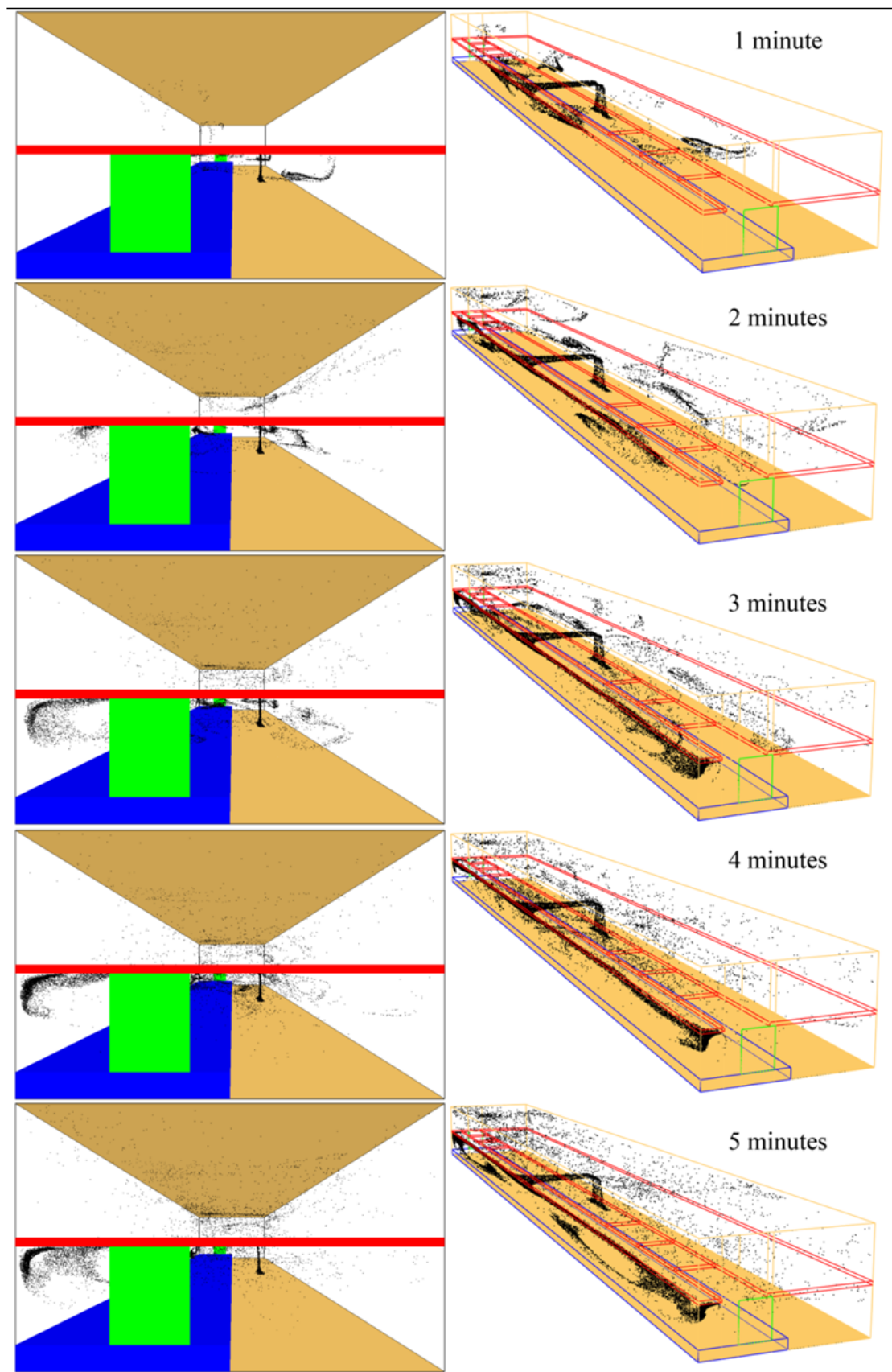

Figure 9. Two mechanical fans located on both sides of underground station B2 as indicated in green colour. Fire load is individually $1 \mathrm{MW}$ and the time is $1 \sim 6$ minutes. Both front (left) and parametric (right) views are presented for comparison of smoke management effects. 

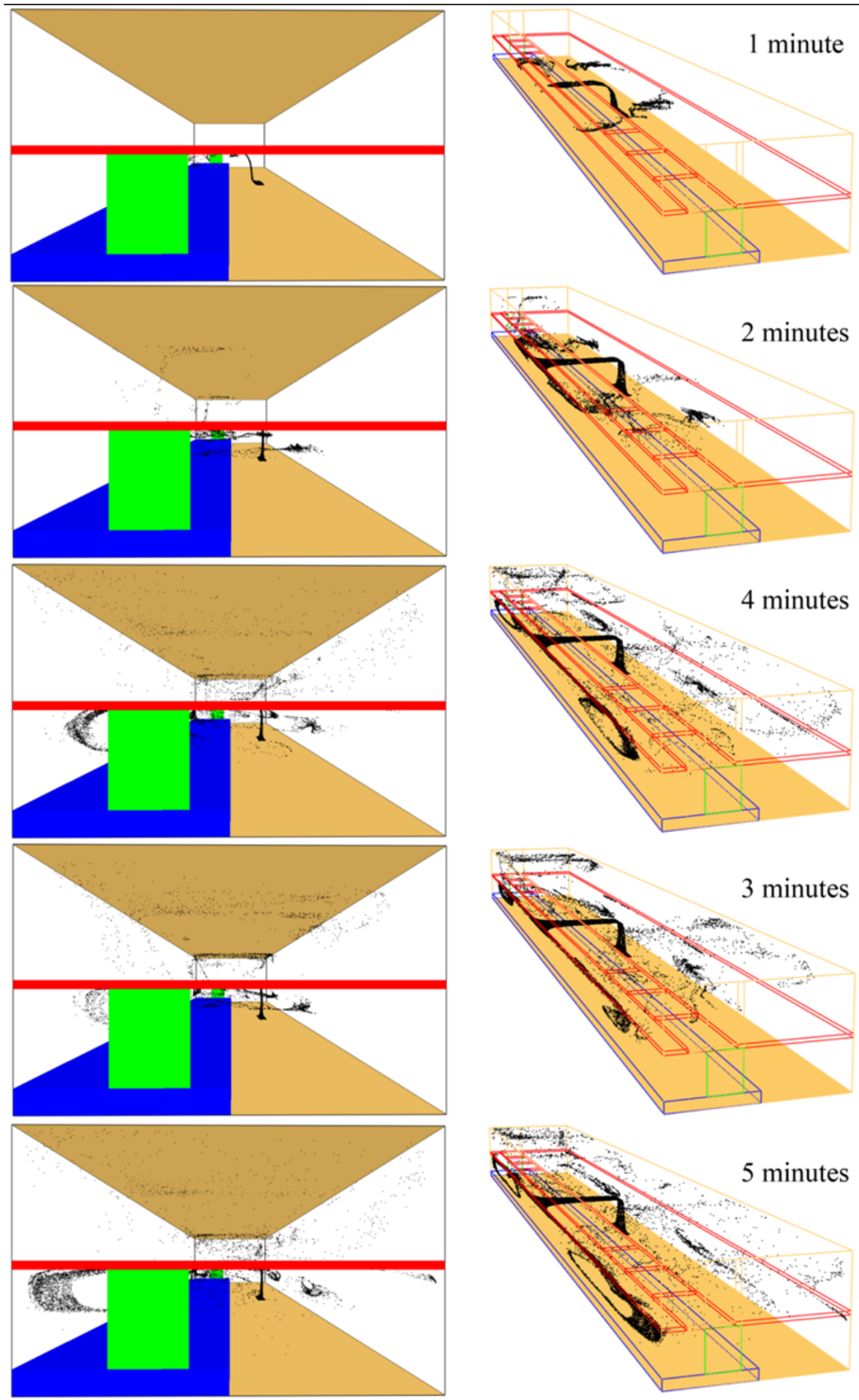

Figure 10. Two mechanical fans located on both sides of underground station B2 as indicated in green colour. Fire load is individually $5 \mathrm{MW}$ and the time is $1 \sim 6$ minutes. Both front (left) and parametric (right) views are presented for comparison of smoke management effects. 


\subsection{Operation mode 2 , two fans operate simultaneously to provide mechanical ventilations}

Two mechanical fans (volume flow rate at $525 \mathrm{~m}^{3} / \mathrm{sec}$ ) located on both sides of underground station B2 as indicated in green colour in Fig.9-10. Fire load are 1MW and 5MW and the time is 1 6 minutes. It is simulated that smoke can be greatly diffused due to fan-driven flows, resulting in less than $1 \%$ area of $1.8 \mathrm{~m}$ smoke height and relatively safe egress mode after 6 minutes of $1 \mathrm{MW}$ fire. Simulation results agree with full scale observations [27] where located fans near escalator area would effectively re-distribute the thermally-induced smoke to the overall ceilings before accumulating in the escape route.

\section{Conclusion}

From the simulations on mechanical ventilation of previous sections, the following conclusions can be drawn:

1. The first case numerically studies the effect of ventilation rates and bathroom equipment locations on the odor removal efficiency in a modeled bathroom. Our study agrees well with the results of a previously published study [9].

2. Qualitatively, numerical calculations result in similar trend such that the influence of ventilation rates and toilet locations on the odor removal is consistent with test data in a mock-up bathroom. Similar conclusion is drawn that higher ventilation rates and shorter distances between the toilet and exhaust air vent are found to be more capable of raising local air quality and the removal efficiency of odors.

3. Quantitatively, two indexes of QI and ORE, are employed for the analysis of the ventilation effect. The experimental results indicate that doubling the flow rate of supply air from 8.5 to $17 \mathrm{ACH}$ leads to a moderate $4 \%$ increase in ORE, while the result of our numerical study is found that doubling area of exhaust vents leads to a moderate $30 \%$ increase in ORE in $8.5 \mathrm{ACH}$ rates. That is, if we want design bathroom from the point of view's energy-saving, the new idea is that increasing exhaust-vent area also arise more efficient of ventilation system than enhancing $\mathrm{ACH}$ rates.

4. The second case study aims to numerically investigate the operation modes of mechanical ventilation in underground tunnels and compare the CFD effectiveness with full-scale experiments and existing fire codes in Taiwan. We numerically investigate the effectiveness of the smoke control systems via mechanical ventilation. In particular, focus is placed on safe egress time in different operation modes and comparison with full scale experiments as well as fire codes in Taiwan. The following conclusions can be drawn from simulation results.

5. Fire scenarios are very complex phenomena and these are especially true for the cases of underground channels and subway stations. It is simulated that for the case of Nangkang North Tunnel in Taipei area, the worst case scenario of mechanical failures in ventilation systems will still hold the egress time of six minutes or more under fire loads of 1 and 5MW, respectively. The conservative design criterion is in compliance with NFPA 130 and domestic fire codes in Taiwan. Moreover, it is imperative to 
perform full-scale experiment for special structures such as underground station, i.e., performance-based fire codes and our simulation results agree well experiments.

6. Current design of underground station in Taiwan relies heavily on the smoke storage space to extend the egress time while the mechanical ventilation systems have only a minor contribution in smoke management. On the other hand, mechanical ventilation systems can play a more significant role in rescue mission after successful personnel evacuation. For example, numerical results indicate that smoke chimney effect can be effectively dispersed through mechanical ventilation to both safeguard firefighters and rescue members.

7. In terms of smoke control strategy, transient simulations are imperative in order to test the fire codes of various parametric values and different scenarios. Transient simulations allow one to check not only the time required to confine the smoke front, but also the extension of all the surrounding environment which can be potentially occupied by smoke. Educationally, it is also a very good teaching tool to train the firefighters and managers in order to construct a better rescue strategy.

\section{Author details}

Yiin-Kuen Fuh, Wei-Chi Huang and Jia-Cheng Ye

National Central University, Department of Mechanical Engineering \& Institute of Energy, Taiwan, ROC

\section{Acknowledgement}

Thanks for the National Institute of Standards and Technology develop Fire Dynamics Simulator and Smokeview (FDS-SMV).

\section{References}

[1] NIST Special Publication 1018-5, Fire Dynamics Simulator (Version 5) Technical Reference Guide.

[2] W.S. Dols, A.K. Persily, S.J. Nabinger: IAQ '92, Environments for People (1992), p.85.

[3] K.C. Chung, S.K. Wang: Indoor Environment Vol. 3 (1994), p.149.

[4] M. Sandberg, C. Blomqvist: ASHRAE Transaction Vol. 95 (1989), p.1041.

[5] ASHRAE: fundamental handbooks. Atlanta, GA: American Society of Heating, Refrigerating, Air-Conditioning, Inc.(2005).

[6] K.C. Chung, C.M. Chiang, W.A. Wang: Building and Environment Vol.32, No. 2(1997), p.149.

[7] Sandberg M. What is ventilation e1ciency? Building and Environment 1981;16(2):123-35.

[8] K.C. Chung, S.P. Hsu: Building and Environment Vol.36 (2001), p.989.

[9] Y.C. Tung, S.C. Hu, T.Y. Tsai: Building and Environment Vol. 44 (2009), p.1810.

[10] Fire dynamics simulators, http://fire.nist.gov/fds/, accessed in Feb. 14, 2010

[11] K. Hagstrom, A.M. Zhivov, K. Siren, L.L. Christianson: Building and Environment Vol.37 (2002), p.55 
[12] Ministry of Transportation, Taiwan, National fire codes for fire prevention equipments and egress facilities in railway tunnels and underground stations. (2008) (In Chinese)

[13] B. Merci: Fire Safety Journal, Vol. 43 (2008), p.376.

[14] AS 4391 (1999), Smoke Management Systems Hot Smoke Test, Australian Standard

[15] NFPA 130 (2003), Standard for Fixed Guideway Transit and Passenger Rail Systems

[16] E. Kim, J. P. Woycheese and N. A. Dembsey: Fire Technology Vol. 44 (2008), p.137.

[17] K. McGrattan, A. Hamins: Fire Technology Vol. 42 (2006), p.273

[18] J. Tan; Y. Xie and T. Wang: IEEE 2010 International Conference on Mechanic Automation and Control Engineering (MACE) Issue. 26-28 (2010), p.1028 - 1032

[19] M. Jurij: Tunnelling and Underground Space Technology Vol. 18 (2003), p.525

[20] F. Chen, S.-C. Guo, H.-Y. Chuay and S.-W. Chien: Theoretical and Computational Fluid Dynamics Vol. 16 (2003), p349

[21] F. Chen, S.-W. Chien, H.-M. Jang and W.-J. Chang: Continuum Mechanics and Thermodynamics Vol. 15 (2003), p.425

[22] R. Borchiellini, V. Verda: Fire Safety Journal Vol.44 (2009), p.612

[23] C.C. Hwang, J.C. Edwards: Fire Safety Journal Vol. 40 (2005), p213.

[24] Taipei municipal department of underground construction, Ministry of Transportation, Taiwan, Banciao station full-scale tests on fire and smoke management for emergency operation. (1999) (In Chinese)

[25] Underground construction department, Ministry of Transportation, Taiwan, Nangkang North Tunnel demonstration of mechanical ventilation. (2005) (In Chinese)

[26] S. P. Su, Y.H. Tsai: Underground tunnel integration with ventilation-case study, 7th across Taiwan Strait tunnel and underground conference. (2008) (In Chinese)

[27] S. P. Su, Y.H. Tsai: Full-scale experiment on operation modes for underground tunnel ventilation, 8th across Taiwan Strait tunnel and underground conference. (2009) (In Chinese)

[28]D. A. Anderson, J.C. Tannehill, and R.H. Pletcher. Computational Fluid Mechanics and Heat Transfer. Hemisphere Publishing Corporation, Philadelphia, Pennsylvania, 1984. 11, 15

[29] H. Qian, Y. Li, P.V. Nielsen, C.E. Hyldgaard, T.W. Wong, A.T.Y. Chwang: Indoor Air Vol.16 (2006), p.111.

[30] H.Brohus: Personal Exposure to Contaminant Sources in Ventilated Rooms. Ph.D. thesis, Aalborg, Denmark: Department of Building and Structural Engineering, Aalborg University (1997).

[31] W.J. Fisk, D. Faulkner, D. Sullivan, F. Bauman: Indoor Air Vol.7 (1997), p.55. 